\title{
Relation between treatment duration and temperature factors in rheumatoid arthritis
}

\author{
Jolanta Pauk ${ }^{1}$, Agnieszka Wasilewska², Justyna Chwiećko ${ }^{3}$, Izabela Domysławska ${ }^{4}$, \\ Stanisław Sierakowski ${ }^{5}$, Adam Idźkowski ${ }^{6}$, Kristina Daunoravičienè ${ }^{7}$, Julius Griškevičius ${ }^{8}$ \\ ${ }_{1,2,6}$ Bialystok University of Technology, Poland \\ 3, 4,5 Bialystok Medical University, Poland \\ 7,8 Vilnius Gediminas Technical University, Lithuania \\ E-mails: ${ }^{1}$ j.pauk@pb.edu.pl (corresponding author), ${ }^{2}$ a.wasilewska@doktoranci.pb.edu.pl, \\ ${ }^{3}$ chwiecko6@wp.pl, ${ }^{4}$ izadomyslawska@o2.pl, ${ }^{5}$ stanislaw.sierakowski@interia.pl, ${ }^{6}$ \\ a.idzkowski@pb.edu.pl, ${ }^{7}$ kristina.daunoraviciene@vgtu.lt, ${ }^{8}$ julius.griskevicius@vgtu.lt
}

(Received 30 March 2016; accepted 28 April 2016)

\begin{abstract}
Introduction: Rheumatoid arthritis (RA) is a chronic autoimmune disease which results in the loss of joint function and several deformities. The aim of the study was to evaluate the influence of duration of the disease and prescribed treatment on the temperature of RA joints.

Methods: The evaluation was carried out on 30 patients with rheumatoid arthritis and 30 typical subjects as a control group. Thermograms were taken using thermograph camera.

Results: Statistically significant difference was found for ankle joint temperature between the group of patients treated for more than 10 years and healthy subjects.

Conclusions: The observations indicate that mean temperature of the skin above the ankle joint tends to decrease with rising duration of disease course. Progression of a RA leads to an erosive destruction in ankle joint in late stages of a disease.
\end{abstract}

Keywords: rheumatoid arthritis, thermovision, skin temperature.

\section{Introduction}

Rheumatoid arthritis is a chronic autoimmune disease which results in the loss of joint function and several deformities [1]. The duration of disease activity in RA patients is an important factor impacting joint destruction and functional disability [2]. Joint damage often begins within weeks or months after the onset of symptoms and is detectable on radiographs within 2 years [3]. There are now three main combinations that play substantial role: MTX+sulfasalazine (SSZ)+hydroxychloroquine, MTX+leflunomide (LEF), and MTX+biologics. Landewe et al. [4] administered the treatment combined of SSZ, MTX, prednisolone or SSZ monotherapy. Combination treatment during the 4-5 years presented greater decrease of sharp progression rate. Hetland et al. [5] described the therapy which include: MTX + cyclosporine + intra-articular glucocorticoid betamethasone. The authors report a delay to progression of erosions in patients at 2 years. Mottonen et al. [6] used a combination of DMARDs (SSZ, MTX, HCQ), and prednisolone or a single DMARD with or without prednisolone. Combination of 3 DMARDs for the first 2 years limits peripheral joint damage (Larsen scores) for at least 5 years. Smolen et al [7] estimated the effectiveness of the combination of INF + MTX and observed significant benefit with regard to the destructive process, clinically relevant improvement in physical function and quality of life. However, currently available techniques used for assessing treatment efficacy present limitations. For example, ultrasound is a highly user- dependent method and MRI requires administration of contrast agent and sedation in case of children [8]. Progressing inflammatory process in joints result in rise of the warmth of skin surfaces covering the joint and its temperature may be measured by non-invasive technique called thermovision. Thus, the aim of the study was to evaluate the influence of duration of the disease and administered treatment on the temperature of RA joints.

(C) 2016 The Authors. Published by VGTU Press. This is an open-access article distributed under the terms of the Creative Commons Attribution License (CC-BY 4.0), which permits unrestricted use, distribution, and reproduction in any medium, provided the original author and source are credited. 


\section{Methods}

The evaluation was carried out on 15 patients of up to 10 years duration of RA, 15 patients with RA lasting more than 10 years and 30 typical subjects as a control group, aged between 4480 years old. All the patients had RA diagnosis according to the standards of the American College of Rheumatology [9] and were free from any coexistent disease that could influence the outcome. None of the participants in the control group had a known health problem that would interfere with their performance. The patients were identified and selected at Medical University of Bialystok Hospital's Rheumatology Clinic, Poland. At the beginning of the procedure, one medical doctor conducted a questionnaire to gain basic data (age, height, weight) and DAS28 (disease activity score). Inclusion criteria for patients recruited for the study included: age above 18 years old, the duration of treatment above 1 year. Patients were excluded if they were under the age of 18 years, the duration of treatment under 1 year, rheumatoid factor below $50 \mathrm{IU} / \mathrm{mL}$. The patients participated in the study with their consent, according to the declaration of Helsinki and the approval of the Ethical Committee. Thermograms were taken in a sitting subject position in room temperature of $23 \mathrm{deg}$. Centigrade. The thermographic camera (Thermo GEAR G100, NEC Avio) was used. Camera was placed perpendicularly to the scanned surface. Measurements were taken at the distance of $1.5 \mathrm{~m}$ from the subject. Pictures of both hands and feet were taken simultaneously. Computer software Statistica 12.5 (StatSoft, Tulsa, OK, USA)) was used for analysis.

\section{Results}

Comparison between patients undergoing biological treatment, patients without biologicals and typical subjects did not reveal any substantial difference $(p>0.05)$. However, the authors observed different joint temperatures for various durations of treatment. Statistically significant difference was found for ankle joint ( $\mathrm{p}<0.05)$. According to the observations the mean ankle joint temperature is significantly lower in RA > 10 years group compared with typical subjects (Tab. 1).

Table 1. The temperature $\left[{ }^{\circ} \mathrm{C}\right]$ of selected parts of lower limbs

\begin{tabular}{|c|c|c|c|c|c|}
\hline Joint & Group & $\begin{array}{l}\text { Mean } \\
(\mathrm{SD})\end{array}$ & $\begin{array}{c}\text { Difference } \\
\text { RA }<10 \text { years } \\
\text { vs. typical } \\
\text { subjects }\end{array}$ & $\begin{array}{c}\text { Difference } \\
\text { RA > } 10 \text { years } \\
\text { vs. typical } \\
\text { subjects }\end{array}$ & $\begin{array}{c}\text { Difference } \\
\text { RA }<10 \text { years } \\
\text { vs. } \text { RA > } 10 \\
\text { years }\end{array}$ \\
\hline \multirow{3}{*}{$\begin{array}{l}\text { Metatarsophalangeal } \\
\text { joints }\end{array}$} & $\mathrm{RA}<10$ years & $\begin{array}{l}30.3 \\
(2.7)\end{array}$ & \multirow{3}{*}{0.4} & \multirow{3}{*}{-1.5} & \multirow{3}{*}{1.9} \\
\hline & $\mathrm{RA}>10$ years & $\begin{array}{l}28.4 \\
(2.9)\end{array}$ & & & \\
\hline & Typical subjects & $\begin{array}{l}29.9 \\
(1.7)\end{array}$ & & & \\
\hline \multirow{3}{*}{ Ankle joint } & $\mathrm{RA}<10$ years & $\begin{array}{l}31.3 \\
(1.7)\end{array}$ & \multirow{3}{*}{-0.2} & \multirow{3}{*}{$-0.9 *$} & \multirow{3}{*}{0.7} \\
\hline & $\mathrm{RA}>10$ years & $\begin{array}{l}30.6 \\
(0.6)\end{array}$ & & & \\
\hline & Typical subjects & $\begin{array}{l}31.5 \\
(0.8)\end{array}$ & & & \\
\hline
\end{tabular}

Note: $*$ - statistically significance $(\mathrm{p}<0.05)$

\section{Conclusions and discussion}

Rheumatoid arthritis in its early stages tends to affect smaller joints, mostly the joints of hand, toes and feet. Progression of the disease may lead to the involvement of bigger joints: wrists, knees, ankles, elbows, hips and shoulders. Belt [10] used radiographs to estimate the relation between RA timing and destruction process of the ankle and subtalar joints. At the 15-year follow- 
up the authors detected a total of 17 ankles with minor changes in 15 patients. At the 20 -year follow-up nine ankles of seven patients presented major changes, and 12 ankles of 11 patients' minor changes. Major changes were described as ankles with marked erosions and/or destroyed joints with no joint space left. In current study the authors observed significantly lower joint temperatures in late stages of a disease (> 10 years duration) compared with healthy subjects. Rasmussen et al. demonstrate that degenerative process in joints can result in hypothermia [11]. Supporting this theory means we can consider our results consistent with observations made by Belt [10]. We provide two possible explanations of the results obtained in this study. Our theories assume that lower ankle joint temperature in late stages of RA can either be a result of long-term anti-rheumatic treatment or an advanced bone degeneration in the area of ankle joint. Joint temperature changes in different stages of RA can be observed with thermovision camera. Thus, apart from prevalent available methods such as radiography, thermovision should also be considered as diagnostic tool for assessing bone erosions.

\section{References}

[1] Cojocaru, M., et al. 2010. Extra-articular Manifestations in Rheumatoid Arthritis, Maedica (Buchar) 5(4): 286-291.

[2] Aletaha, D., et al. 2009. Rheumatoid arthritis joint progression in sustained remission is determined by disease activity levels preceding the period of radiographic assessment, Arthritis \& Rheumatology 60(5): 1242-1249. http://dx.doi.org/10.1002/art.24433

[3] Plant, M. J., et al. 1998. Patterns of radiological progression in early rheumatoid arthritis: results of an 8 year prospective study, Journal of Rheumatology 25(3): 417-426.

[4] Landewe, R. B., et al. 2002. COBRA combination therapy in patients with early rheumatoid arthritis: long-term structural benefits of a brief intervention, Arthritis \& Rheumatology 46(2): 347-356. http://dx.doi.org/10.1002/art.10083

[5] Hetland, M. L., et al. 2006. Combination treatment with methotrexate, cyclosporine, and intraarticular betamethasone compared with methotrexate and intraarticular betamethasone in early active rheumatoid arthritis: an investigator-initiated, multicenter, randomized, double-blind, parallel-group, placebo-controlled study, Arthritis \& Rheumatology 54(5): 1401-1409.

http://dx.doi.org/10.1002/art.21796

[6] Mottonen, T., et al. 1999. Comparison of combination therapy with single-drug therapy in early rheumatoid arthritis: a randomised trial. FIN-RACo trial group, Lancet 353(9164): 1568-1573. http://dx.doi.org/10.1016/S0140-6736(98)08513-4

[7] Smolen, J. S.; Han, C.; Bala, M. 2005. Evidence of radiographic benefit of treatment with infliximab plus methotrexate in rheumatoid arthritis patients who had no clinical improvement: a detailed subanalysis of data from the anti-tumor necrosis factor trial in rheumatoid arthritis with concomitant therapy study, Arthritis \& Rheumatology 52(4): 1020-1030. http://dx.doi.org/10.1002/art.20982

[8] Spalding, S., et al. 2008. Three-dimensional and thermal surface imaging produces reliable measures of joint shape and temperature: a potential tool for quantifying arthritis, Arthritis Research \& Therapy 10(1): 1-9. http://dx.doi.org/10.1186/ar2360

[9] Tepperman, S. P., Delvin, M. 1986. The therapeutic use of local heat and cold, Canadian Family Physician 32: 1110-1114.

[10] Belt, E. A.; Kaarela, K.; Lehto, M. U. K. 1998. Destruction and reconstruction of hand joints in rheumatoid arthritis. A 20-year follow-up study, Journal of Rheumatology 25(3): 459-461.

[11] Rasmussen, L. K.; Mercer, J. B. 2004. A comparison of thermal responses in hands and feet of young and elderly subjects in response to local cooling as determined by infrared imaging, Thermology International 14(2): 71-76. 